\title{
La vie prodigieuse de Bernard-François Balssa (père d'Honoré de Balzac)
}

\section{Annie Duprat}

\section{(2) OpenEdition \\ 1 Journals}

\section{Édition électronique}

URL : https://journals.openedition.org/ahrf/1035

DOI : 10.4000/ahrf.1035

ISSN : 1952-403X

Éditeur :

Armand Colin, Société des études robespierristes

\section{Édition imprimée}

Date de publication : 1 mars 2001

Pagination : 126-127

ISSN : 0003-4436

\section{Référence électronique}

Annie Duprat, «La vie prodigieuse de Bernard-François Balssa (père d'Honoré de Balzac) », Annales historiques de la Révolution française [En ligne], 323 | janvier-mars 2001, mis en ligne le 10 avril 2006 consulté le 24 avril 2022. URL : http://journals.openedition.org/ahrf/1035 ; DOI : https://doi.org/ 10.4000/ahrf.1035

Ce document a été généré automatiquement le 24 avril 2022.

Tous droits réservés 


\title{
La vie prodigieuse de Bernard- François Balssa (père d'Honoré de Balzac)
}

\author{
Annie Duprat
}

\section{RÉFÉRENCE}

Jean-Louis Déga, La vie prodigieuse de Bernard-François Balssa (père d'Honoré de Balzac), Rodez, Éditions Subervie, 1998, 667 pages, index des noms propres, sources manuscrites, notes et bibliographie. Préface par Roger Pierrot, conservateur en chef honoraire à la Bibliothèque nationale de France.

1 On connaît à présent mieux les liens affectifs, mais également pour partie idéologiques, qui unissaient Honoré de Balzac à la Révolution, grâce à la récente étude de RenéAlexandre Couteix, Balzac et la Révolution(1). Un de ses personnages, l'illustre parfumeur César Birotteau, ne cesse d'ailleurs de rappeler ses hauts faits sur les marches de l'église Saint-Roch, aux côtés de Bonaparte, pour sauver la République lors du coup d'État de Vendémiaire. On ne connaissait guère jusqu'à présent la vie, pourtant bien romanesque de son père, né Balssa en 1746, devenu Balzac sans que l'on puisse guère déterminer avec précision à quelle date, entre 1773 et 1783. Jean-Louis Déga, arrière-petit neveu de son héros, nous livre une volumineuse biographie qui se présente comme une étude minutieuse de la généalogie familiale des Balzac mais dévoile également les vrais patronymes de nombre des héros du romancier Balzac.

2 L'ouvrage s'ouvre sur les années de jeunesse de Bernard-François Balssa, fils aîné d'une nombreuse (onze enfants) famille de paysans du Ségala. En 1766, une jeune fille le traîne en justice sous l'accusation de «gravidation», donc de viol. Incarcéré, il ne doit la liberté qu'au paiement d'une caution par son père qui, pour cela, doit vendre une terre. Ce scandale décide le jeune Balssa à se rendre à Albi où il devient clerc de notaire puis clerc de procureur, puis à Toulouse, puis à Paris, où il est secrétaire auprès de Bertrand 
de Molleville, conseiller au Parlement. A-t-il prononcé la fameuse phrase «à nous deux, Paris», lorsqu'il s'installe dans la ville-lumière au début de l'année 1772 On ne le saura pas, mais en vérité une vie nouvelle s'ouvre à lui.

Employé par l'administration des Domaines de la Couronne, il devient secrétaire au Conseil du Roi en janvier 1776 et conserve cette charge jusqu'en 1794. Administrateur tenace et efficace, il se fait rapidement une réputation et une place dans la société. Il s'enrichit mais, même à la tête d'un capital évalué à environ 20000 livres, s'il n'a pas encore choisi d'acquérir une charge anoblissante, il commence à exprimer des doutes sur la pérennité du système de gouvernement et de la société française en ces dernières années du xvirlesiècle. Il serait même devenu le «jacobin Balzac», selon Jean-Louis Déga. La Révolution n'assombrit pas l'étoile de notre Balzac père, qui entretient les meilleures relations du monde avec un de ses parents, Lacombe Saint-Michel, député du Tarn à l'Assemblée législative puis à la Convention, tout en jouant de ses utiles relations au service du roi dans le réseau de son premier "patron», Bertrand de Molleville. À la suite de la disgrâce de celui-ci, il perd son emploi au ministère de la Marine en 1792, mais, grâce à Lacombe Saint-Michel, Balzac se place immédiatement comme trésorier au bureau central des fourrages de l'armée du Nord. Au sein de sa section à Paris, dont il est le commissaire, il participe à la préparation du 10août 1792 membre du conseil général de la Commune de Paris au début de 1793, il est à la fois l'un de ces militants de la sans-culotterie parisienne d'origine bourgeoise dont Albert Soboul nous avait dressé le tableau dans sa thèse, mais aussi, selon Jean-Louis Déga, un entremetteur jouant double jeu pour renseigner les réseaux d'espionnage de l'ancien ministre Bertrand de Moleville. En avril 1794, Balzac père fuit la guillotine qui s'abat sur les Indulgents et rejoint un poste de directeur des vivres à Soissons. Mais, si JeanLouis Déga suppose qu'il avait des liens secrets avec les dantonistes, il n'en donne pas la preuve.

4 En 1795, il s'installe à Tours comme directeur des vivres et des subsistances. Dans cette cité dont un archevêque du début du xviIIe siècle se nommait... Rastignac, le jacobin se mue en notable, fonde une famille (le jeune Honoré naît en 1779). Adjoint au maire en 1803, administrateur de l'hôpital, il devient franc-maçon (loge de la Parfaite Union) et œuvre dès lors pour l'amour de l'Humanité. En février 1814, il retourne à Paris comme directeur des vivres pour la première région militaire de la France, avec un bon traitement. On sait que lors de la Restauration, Louis XVIII entreprend une politique d'amnésie d'État, visant à faire oublier aux Français à la fois la Révolution et l'Empire. Balzac publie un Opuscule sur la statue équestre que les Français doivent faire ériger pour perpétuer la mémoire de Henri IV et de leur amour envers sa dynastie... Ce texte traduit-il un profond sentiment de ralliement à la monarchie des Bourbons ou simplement le souci de protéger sa situation bien confortable de notable Mais nombre de «girouettes» de ces temps troublés ont été conduites à de pareilles reptations... Prudente également est sa conduite lors du procès de son frère, accusé de meurtre et guillotiné en 1819. Balzac père se retire enfin à Versailles où il meurt le 19 juin 1829. Sur sa tombe, au cimetière parisien du Père-Lachaise figure une inscription qu'il avait lui-même choisie, «Balzac Bernard-François, Ancien secrétaire au Conseil du Roi». A-t-il voulu en choisissant pareille épitaphe affirmer son appartenance indéfectible à un monde à jamais révolu ou mettre en exergue la fonction dont il était le plus fier

5 Les pages consacrées à la jeunesse de Balzac père, à ses relations, à ses réseaux d'amitié et de parenté se lisent avec beaucoup de plaisir cependant, on regrettera l'absence de 
tableaux généalogiques récapitulatifs qui permettraient au lecteur distrait de se retrouver dans la forêt dense de tant de personnages. D'autre part, beaucoup d'affirmations ne sont pas étayées sur des dépouillement d'archives et des vérifications scientifiques plus rigoureuses. La biographie du père de Balzac tient donc parfois davantage du roman que du livre d'histoire, mais ces remarques n'entament en rien le plaisir de la lecture et de la découverte du père du plus grand romancier français du XIX ${ }^{e}$ siècle. 